\title{
"Ablaze for God": Constructing and Negotiating Identities in an African Pentecostal Church
}

\author{
Ama Boatemaa Appiah-Kubi \\ Centre for International Studies, Ohio University, Athens, Ohio \\ Andy Ofori-Birikorang \\ Department of Communication and Media Studies, University of Education, Winneba
}

\begin{abstract}
The Church as an organization provides a wealth of research opportunities to explore how the process of identity construction and negotiation function. The present work, therefore, is a study of members' identity construction and negotiation in an African Pentecostal Prayer Camp, Moment of Glory Prayer Army (MOGPA). Through the theoretical frameworks that build on the constructs of communication theory of identity and the identity negotiation theory, this ethnographic study explores the identities constructed by the members of this organization and how they negotiate those identities in their quest for physical and spiritual wholeness. An analysis of the data collected shows that participants through their performances at the prayer camp gatherings construct multifaceted personal, gender, social, ethnic and professional identities. The ethnographic study also revealed that in negotiating their identities, the strategies adopted by participants included acts of adornments, socialization and immersive participation. The study concluded that identity construction and negotiation of members come through the process of social interactions and learning and impacted by the identity of the Prayer Camp's.
\end{abstract}

Keywords: Identity negotiation, ethnography, prayer camp, Pentecostalism, social interaction

DOI: $10.7176 /$ RHSS/10-24-03

Publication date: December $31^{\text {st }} 2020$

\section{Introduction}

Identity construction and negotiation are very important key factors in every social interaction. We learn about our identities and that of others through negotiations with family, peers, organizations, institutions, and the media among others. In our everyday lives, we make connections with people that tend to either re-establish or reiterate our identities. Identity, therefore, becomes the end product of our experiences pieced together and materializes through an ongoing process of identification and change; a socially and historically constructed concept which involves life experiences, relationships and representation of thoughts and emotions in an expressive way creating a reflection of who we are and what we are (Dowling, 2011).

Notably, the most significant factors that impact a person's identity are the cultural and religious settings in which they are nurtured and immersed. To most people, religious settings, sites and platforms as well as the beliefs and doctrines incorporated therein become central parts in the formation of their identities.

Emerging African Pentecostal churches and prayer camps, over the years, for instance, have become places for the solitude and hope for many in the world. With the notion of helping to solve numerous material and nonmaterial problems, churches and prayer camps have become growing sites for the coming together of people from multiple and diverse backgrounds. Hunt (2002) adds to this by contending that as a vibrant form of Christianity, Pentecostalism has long been understood as a faith relevant to the needs of people in dealing with the problem of deprivation and marginalization (Hunt, 2002). However, its changing theodicies and value-orientation have more recently come to assist the formation of identity. The diversity, even within the church, defines how members connect to each other and, as well, establish their identities. With its large numbers and diversified population, where intercultural communication is the norm, identity construction and negotiation, therefore, become highly anticipated.

In various ways, the interaction between and among members of a religious group either reinforces or challenges existing relationships. The interaction thus involves a conscious process of construction and negotiating of identities that are enmeshed in complex dynamics of status that reflect historical and current realities. This is to mean that identities are subjected to constant negotiations. Therefore, identity construction and negotiation present a way by which a newcomer becomes part of a community (Golde, 1998; Lave \& Wenger, 1991; Sweitzer 2009) and it becomes the desire of every individual to be accepted in any environment. Nonetheless, it is important to establish that churches and, for that matter prayer camps, are established to provide a medium for human spiritual experiences (Ammerman, 2005) and, as such, structured around a set of organizational unique beliefs and purposes. Therefore, identity negotiation of members is, as a matter of fact, seen through the constructs of formal structure and identity of the church. In trying to find a balance between who they are and what they have become, therefore, people constantly present themselves and negotiate their behaviours in order to become acceptable. The negotiation process, hence, comes through the process of communicating and representing what the church stands 
for (Gesler, 2013). Given that identity is not a static construct but adjusts and changes based on personal and social factors, exploring identity as it relates to membership negotiation is important.

\section{The need for the study}

Hunt (2002) contends that religion has become a beckoning force in the construction of identities and renders itself an obvious field of enquiry. This is so because religion provides a universal function of allowing an interpretation of the world as human beings experience their place in it. However, in recent sociological works, the link between religion and identity has not been advanced or given the focus that is expected. Certainly, studies that hinge on identity and religion, in this respect, constructions and negotiations of identity in a religious setting remain an under explored theme. The works that have been done in the area, for example, that of Touli (1993), looked at how the church setting provides the focus of identity of a young West African migrant ethnic group within the context of religious beliefs and Praxis (1993). Others have also looked at the importance of religion in aiding the construction of the identities of black immigrants in Britain and the organizational identification and identity negotiations of leaders within a formal structured charismatic church (Gesler, 2013; Hunt, 2002). In general, several works have been done on identity construction and identity negotiation from different perspectives (Agboada \& Ofori-Birikorang, 2018; Bucholtz \& Hall, 2005; Hatoss, 2012; Ofori-Birikorang, 2014; Osartti \& Riemer, 2012).Minimal studies, however, have focused on the identity construction and negotiation of members within African Pentecostal Prayer Camps and religious settings. This paper, therefore, demonstrates the complexity of identity construction and negotiation within a highly participative and belief driven African Pentecostal movement, Moments of Glory Prayer Army (MOGPA) in Ghana. It seeks to investigate the importance of religion (Pentecostalism) in aiding the construction and negotiation of identities. It focuses on identifying the kinds of identities members of this Pentecostal sect construct during their prayer camp gatherings and examine how the members negotiate such identities. This paper is based on the assumption that the process of identifying and being accepted as a part of any organization is a component of identity construction and negotiation which facilitates the connection, attachment and inclusiveness of the members in that particular organization. As a result, we seek to investigate them following research questions:

1. What kinds of identities do members of MOGPA construct during prayer camp meetings?

2. How do members negotiate their identities during the prayer camp meetings?

It is anticipated that the findings of the study would yield vital information that could contribute to research on Pentecostalism in Africa. We hope to develop a better understanding of the church as a communicatively constituted organization and provide insights into identity construction and negotiation of congregants. More importantly, this work would inform leaders of the religious sect being studied and all others on how best to communicate to members of the group by first taking into consideration individual's multifaceted identities and, second, creating an environment that facilitates easy member identification and inclusion. This is also to create an interpersonal space where members, in the process of identity negotiation, freely get to achieve their quest for wholeness in the church and religious environment.

\section{Identity Negotiation Theory}

The term identity negotiation according to Swann (1987), originated in social psychology. Nevertheless, Jackson (2002) contends that "negotiation of identity" is a general concept that has been in existence since the beginning of humanity and emerged first in the field of communication via the work of Stella Ting-Toomey. According to Chatman, Eccles and Manchuk (2005), identity is a "thing that" resides in a person. It is an ongoing dynamic process during which individuals establish, evaluate, re-evaluate and re-establish who they are relative to others in the environment. In view of this, Erikson (1968) is of the conviction that such a process is inherently dependent on the context in which individuals find themselves. Ting- Toomey (2015) avers that the term identity in the Identity Negotiation Theory refers to an individual's multifaceted identities of cultural, ethnic, religious, social, class, gender, sexual orientation, professional, family/relational role, and personal image(s) based on selfreflection and other categorizations of the social construction processes. Orbe (2008) also asserts that identities simultaneously revolve around both individual and social aspect of identification.

According to Goffman (1959), identity is the "dramatic effects" of social interactions. To him, people put up "performances" when they engage in social interactions with one another. That is, they assume a "role" and try to create a favourable "impression" as much possible. From this perspective, Goffman argues that identity is closely related to the performances we create in our everyday lives. Thus, identity is simply the sum of all the roles we play in our lives and not an essence in itself. Rather it is the socially constructed result of all our engagements with others.

Further to this, Ting-Toomey (1999), postulates that identity is the reflective self- conception or self-image derived from our cultural, ethnic and gender socialization processes. It is acquired via our interaction with others in particular situations and a reflective view of a person's self, and this reflection is relevant to his or her culture. She further argues that identities are created through negotiation anytime we assert, modify or challenge our own 
or others self-identification (Ting-Toomey, 1999). Littlejohn and Foss (2011) add to this by asserting that the formation of identity begins early in the family setting where we start to internalize various personal and social identities. According to them, personal identities are the unique characteristics with which we associate ourselves and learn through family interactions and which, subsequently, become an essential aspect of our social identity (Littlejohn \& Foss, 2011).

Although, personal and social identities are equally important, Littlejohn and Foss (2011) and Ting-Toomey (2005) also place much premium on cultural and ethnic identities, particularly the negotiations that occur when we communicate within and between cultures. According to Littlejohn and Foss (2011), cultural identity is related to some attachment to a religious group, region, country or an organization and defined in a large measure by the affiliation we feel. Ethnic identity on the other hand, promotes an association with an ancestry or a group history across generations connected to national origin, race, religion or language. Both cultural and ethnic identities are characterized by value content and salience. Value content has to do with the evaluation one makes based on his or her cultural beliefs whereas salience is the sense or feel of relevance one attaches to his or her cultural beliefs. Littlejohn and Foss (2011) further indicates that there is more stability and security when one communicates within a familiar cultural group than across culture as one may experience vulnerability, change and unpredictability. However, some individuals with a strong sense of self are able to understand and respect the identity of others and allow the latter to also have their own sense of identity. At this stage the individual is categorised as falling into of a state functional biculturalism. If the individual transitions to this state by shifting from one cultural context to the other mindfully and easily, that person becomes culturally transformed. Nonetheless, this can only be achieved by being conscientiously aware of other people's culture; understanding the importance of cultural and ethnic identities and seeing their importance to others; and, finally, having the ability to negotiate identities through observation, listening, politeness, empathy, non-verbal sensitivity and collaboration (Littlejohn \& Foss, 2011; Ting Toomey, 2005). In this sense, our identities are shaped and moulded during interactions with others and are always emerging through interactions (Alexander, 2011). Giving reasons for negotiating identities, Swann (1996) avers that people negotiate their identities in order to establish them in ways that will increase the probability of coherence within the culture or interacting group. Indeed, effective identity negotiation is achieved when parties involved in interaction feel understood, respected and valued.

\section{Communication Theory of Identity}

Identity has been explored by different scholars from varied dimensions. Nevertheless, primarily attributable to Hecht, Collier and Ribeau (1993), the Communication Theory of Identity (CTI) expounds that identity is constructed simultaneously through individual, social and communal engagement. Identity is not static but rather an ongoing and emerging process; it is the multilayered ways through which individuals and communities socially construct themselves (Hecht \& Choi, 2012). It is a joining point between the individual and the society made possible through communication. CTI elucidates that individuals internalize social interactions, relationships, and a sense of self into identities through communication. In turn, identity is expressed or enacted through communication (Hecht \& Choi, 2012). Therefore, the embodiment of a person in relation to what the person is, in their own eyes as well as what others say about them is established through social interactions across life span. Communication thus becomes the means by which identity is established and the mechanism by which it changes as well (Littlejohn \& Foss, 2011). According to the theory, identity does not only define a person but it is also a reflection of social roles and relations through communication.

More so, CTI conceptualizes identity as a collective or group quality and a form of social construction. As a result, CTI suggests that there are two dimensions of identity, namely: the subjective dimension which has to do with the personal sense of self and the ascribed dimension which dwells on the perspectives of others about you. These two dimensions interact in series of four layers of identities: personal, enacted, relational, and communal layer that interact with one another (Hecht, 1993). The personal layer consists of an individual's sense of the self within a social situation. These identities consist of feelings and ideas about oneself, who you think you are and what you think you are like. The enactment layer emphasizes what others think about you based on what you do, what you have and how you act. It is a performed or projected identity. The third which is relational, focuses on who you are in relation to other individuals. This kind of identity gets constructed in an individual's interaction with a relational partner. With this kind of layer, identity is not strictly individual but is attached to the relationship itself. The communal layer focuses mainly on one's attachment to a larger a group or culture. It comes to fruition anytime an individual pays particular attention to what the community thinks or does.

\section{Membership Negotiation}

Membership negotiation presents ways in which members of an organization, both new and old, become and remain part of an organization (McPhee \& Iverson, 2009). It involves an individual's interaction with an organization in order to establish a place and relationship within the organization by engaging with the organization as well as members within it. The process of membership negotiation thus requires having knowledge about the 
organization, being recognized by others and having access to information leading to active involvement and participation (McPhee \& Iverson, 2009). Essentially, membership negotiation provides a means to discuss the induction and maintenance of being a member of an organization and is at the root of what it means for an individual to belong to that organization. Membership negotiation, therefore, becomes an important element for individual identification in any environment, especially when the person is new in the organization and the organisation presents diverse ways in which the individual can connect and identify with a particular environment leading do some form of inclusion.

The church through its structure, amongst other constructs, impacts the construction and negotiation of identity through certain processes the individual member goes through (Gesler, 2013). Though there is an inherent complexity to be recognized, the process of membership negotiation is similar to the process of social learning (Bandura, 1971). Thus, the process of identifying with or being part of a particular organization is a process of learning to function within the organization. Induction into being a member within an organization is not an isolated or individualized occurrence, but a social process. Individuals engage with others to gather the knowledge sets required for being a member. A portion of that process is enacted within the formal structure of the organization, but a portion is also enacted through informal interactions. Thus, membership negotiation can be seen as a process of constructing meaning about and within the organization by learning about the formal and informal structures through social processes (Gesler, 2013).

\section{Methodology}

Data for the study were gathered using naturalistic methods including participant observation, interviews and focus groups discussions. Observations included fifteen months of immersion in the church gatherings and meeting. Indepth interviews and focus group discussions with 24 informants were also conducted. The study hinged on ethnographic design over a prolonged period of time. This length of time in the field allowed us to study the shared patterns of behavior, language and actions of the church as a cultural group in their natural setting. (Creswell, 2013; Halai, 2006, Hancock, 2002). The ethnographic study afforded us the opportunity to immerse ourselves in the social setting (MOGPA), observing and asking questions about the manner in which the people interact, collaborate and communicate (Daymon \& Holloway, 2011). Observations were recorded using fieldnotes and headnotes when immediate note taking was not an option (Lindlof \& Taylor, 2002). We continuously made ourselves available at almost all MOGPA meetings to the point where we were tagged regular members The regular visits to MOGPA enabled us to gain insight into the social practices and performances of members especially where such social practices, under normal circumstances, could not be gathered by an outsider. We immersed ourselves fully in the daily activities and rituals during the meeting sessions, from praying to dancing and packing of chairs after each meeting session. We reported events as they happened in a more empirical manner. This allowed us to gain insider's perspective of the performances as well as the strategies members use in constructing and negotiating their respective identities. In line with the interpretive approach of ensuring consistency, credibility and being systematic with the data collection process, we regularly compared our ethnographic notes to make sure inconsistences and differing viewpoints were rationalised, reconciled or discussed thoroughly to ensure synchrony.

The findings of the study are in two parts: first, we focus on the identities that are constructed by the members of the MOGPA group; and second, how members negotiate the identities within the group. To arrive at these findings, MOGPA was purposively sampled. We rationalise this data source-(MOGPA) - as being the number one Pentecostal prayer camp in Ghana (Adomomline.com, 2017). To retain depth and richness of the data, we also purposively sampled 24 informants who understood the phenomenon under study and were willing to provide information by virtue of their experience (Bernard, 2002). We carried with us palm-sized note pads in which we took field notes and recorded the behavior and actions of the social actors as well as other events as they unfolded. In situations, where notes could not be taken using the note pads, we used our android cell phones to do the recordings. Overall, we made 68 ethnographic visits to the site.

Interviews and focus group discussions were mostly deployed to elicit views and opinions from the participants in order to gain insight into participants' perspectives and experiences that otherwise could not be observed effectively by other means. Interviews were narrative in manner (Gubrium \& Holstein, 2002) and also included open-ended questions derived from the research questions of the study (Lindlof \&Taylor, 2002).

Two focus groups were formed comprising of seven members each; four (4) men and three (3) women for the first group and four (women) and three (3) men for the second group. The focus group discussions gave us a wider reach to seek divergent views from participants. We moderated the discussion. Most of the interviews were conducted in Asante Twi (one of the widely spoken dialects in Ghana) and later transcribed and translated with the help of a professional translator. However, other interviews were conducted in the English language with informants who speak and understand the language. There was minimal pressure for the individuals to answer in specific ways.

The data collected were closely and carefully assembled and prepared. Through a careful engagement and 
examination, patterns and themes were drawn (Adu, 2019: Braun \& Clarke, 2006). This was done in order to have a clear view, description and understanding of the issues that emerged from the data in greater detail (Flick, 2013). After having a full grasp of the issues in the data, certain descriptive themes emerged and these themes were interpreted using concepts and theories to draw meanings from responses gathered from our informants. Direct quotations were also used to support the interpretations and discussions. Throughout the research process, we managed our own subjectivity by recognizing the subjective nature of qualitative research, grounding all our work in established theoretical constructs and utilizing concepts in literature. These theories and concepts were used as the lens for viewing the data collected and served as the basis for the understanding of the phenomenon under study.

\section{Findings and Discussion}

The members of MOGPA construct multifaceted identities and enact their negotiations, in part, by identifying with the church through a process of social learning and actively interacting with the people to gain insights into the structure and constitution of the Army. Generally, the construction and negotiation of the identity of members resonate with the theoretical constructs and concepts examined in this paper. For members of MOGPA, identity construction and negotiation occurred through wearing of MOGPA adornments, socialization and members' active participation. The negotiation strategies, therefore, enabled the social actors to negotiate multifaceted identities at the personal, ethnic/geographic, gender, professional and social levels. Negotiations also enabled members to take on another form of identity: being prayerful.

\section{Identity Construction at MOGPA}

Burke and Stets (2009) elucidate how individuals construct several identities over the course of a lifetime, and how at any point in time any of the identities could be activated. Such identities, according to Hecht and Choi (2012), are simultaneously individual, social and communal. Identity is not static but rather an ongoing and emerging process. Hecht and Choi (2012) further aver that individuals internalize social interactions, relationships, and aspects of the self into identities through communication. Butler (1990) supports this claim with the assumption that identity is not something that one "has", but rather something that one "does", or "performs" and recreates through concrete exchanges, discourses and interactions between human beings. It is for this reason that this study sought to identify the kinds of identities individuals construct at MOGPA. Theorists of CTI view identity as the multilayered ways that individuals and communities socially construct themselves (Hecht \& Choi, 2012). In the same manner, the data revealed that the social actors constructed multiple identities including personal, gender, ethnic/geographic, social and professional.

\section{Personal identity}

The personal identity is the self-concept of a person. It is basically the unique characteristics individuals associate themselves with and is learnt first through family interactions (Littlejohn \& Foss, 2011). According to Hecht and Choi (2012), this layer may be thought of as being analogous to one's self-concept, self- image, self-cognitions, feelings about the self or self-esteem, and/or a spiritual sense of being. Similarly, the social actors in MOGPA, through their performances, constantly presented their real sense of self- who they are- by communicating their feelings, ideas, values, and beliefs. In most instances, the social actors, in introducing themselves, first mentioned their names and other personal qualities which together form part of who they are. They also discussed other characteristics they possessed through our conversations with them as well as in the performances of their activities, most especially, during testimony sharing. Below are some instances:

... My name is Owusu Mensah Carlos. I am between the ages of 20 and 25. I am an SHS graduate. For now, I am an usher in MOGPA...Although, I'm that type of quiet, calm, shy I think I'm a bit of Charismatic too... (FGD 1, Informant 5)

...I'm called Adwoa Serwaa... I'm a very strong person but what happened to me made me sober... (Informant, 9)

The above excerpts indicate how the social actors were telling a story of who they are in relation to their own shared beliefs of what they are made up of. They communicated their own concepts of self. It is therefore evident that the social actors presented their personal identity. This sits well with the personal layer of identity where the individual is a locus or frame of identity. Just as the extracts illustrate, the personal identity of the social actors provided an understanding of how the individuals defined themselves in general as well as in particular situations (Hecht, Collier, \& Ribeau, 1993).

\section{Gender Identity}

Gender is what is put on, invariably, under constraint, daily and incessantly, within a highly rigid regulatory frame that congeals over time to produce the appearance of substance of a natural sort of being (Butler, 1999). When individuals perform gender, it is believed that they are constructing or asserting their gender identity. As argued 
by Butler (1990), gender is not something that one "has", but rather something that one "does", or "performs" and recreates through concrete exchanges, discourses and interactions between human beings. Through participants' daily activities and interactions at MOGPA, the study revealed that the social actors performed their gender and in essence affirmed their gender identity. They acted in ways that were in harmony with societal prescriptions of what is expected by men and women based on their biological make up. For instance, at some points, the men exhibited some sort of socially accepted masculine tendencies by displaying physical strength and emotional control; being bold and going after quests that had to do with economic and financial empowerment. The women on the other hand conformed to quests that had feminine ideals of nurturing, marriage, childbirth, weakness, and being emotional, among others. These occurrences undeniably attest to the fact that most performances of the social actors were gendered. The construction of this gender identity can be explored through the lens of the enactment layer of identity in CTI which stipulates that identity is enacted in communication through messages. In this layer, identity is conceptualized as a performance or as something being expressed. This identity was presented by the social actors in order to position themselves in a certain framework and to also create a certain picture in the minds of people as being 'straight'. Again, it was also to help them gain locus in the environment in which they found themselves. It is against this backdrop that the social actors continuously conformed to the prescriptions and through that, positioning, projected a certain kind of gender identity.

\section{Ethnic/Regional Identity}

According to Littlejohn and Foss (2011), ethnic identity like all other identities, is very important and learnt through social interactions. It consists of an association with ancestry or a group across generations connected to national origin, race, religion and or language. To have this identity, one must show a strong sense of self in terms of feeling, affiliation and belonging to an ethnic group and, most essentially, must place value on it (Epstein \& Heizler, 2015). This assertion was exemplified in the performances of the social actors. Through their enactments, they directly and indirectly presented themselves as belonging to or having an ethnic affiliation. Most of the time such ethnic affiliation manifested through dialect one spoke and the self-introduction made. For instance, during a particular visit, a participant sharing a testimony pleaded with members of the congregation to be patient and lenient with her accent and use of the Twi dialect to express herself as she was not a native speaker. This was because Twi is the dominant medium of interaction at the MOGPA prayer camp. From her accent and her pronunciation of words, one could clearly tell that she hailed from one of the ethnic groups of the northern part of Ghana. On another occasion, a lady sharing her testimony bawled to the audience and solicited the support of the people of similar extraction to join her during the delivery of her testimony. She said:

Indigenes of Konongo, are you here? Do you remember a lady who recently, was involved in an accident and who gave her baby to someone when the car caught fire? I am the one oh!

Although, this lady was calling on the people to join her to share her testimony, she was indirectly also communicating her ethnicity and cultural background as an Asante who hails from the town of Konongo.

It was startling to have also found that social actors from a particular geographic location, usually came in groups to the prayer sessions in buses from their respective destinations. To make their presence known and felt, they either gathered at one place or bellowed out their names during the testimony session anytime one got the opportunity. Again, during most introductions, on the sharing of testimonies and in our interactions with them, the social actors were never hesitant in making their ethnic affiliation and their present geographical location known. Ethnic identity markers included revealing a person's hometown, place of abode, occupation or ethnicity. The following are examples:

... I am Doris. I am an Ashanti. I come from Jamasi but I live at Asenua... (Informant, 3);

... I am Nana Kwasi. I am a Fante but currently because of work, I reside in Kumasi... (Informant, 2)

The excerpts indicate how the social actors placed some amount of premium on their ethnic and geographical background. This kind of identity marker corroborates the communal layer of identity that indicates how identity is formed based on an individual's strong attachment to a larger group or culture.

\section{Social identity}

Social identity is the individual's sense of who they are based on their membership within a social group. Tajfel (1979) explains how membership of groups such as family and social class are important source of pride and selfidentity. This is because such groups give them a sense of social identity and a sense of belonging to the social world. This kind of identity was manifested by the social actors in MOGPA throughout the study. Family and friendship as social groups played a very vital role in the lives of the social actors. Each of the participants had one way or the other visited MOGPA with either a relative or a friend. Nonetheless, those who came alone also built some sort of relationship with those they usually sat closer to or stood beside during the prayer service. In their performances, however, the members ensured that their relationship with the people they had come with was known. Sometimes, they either sat at one place as a family or as friends, had conversations together; prayed together; and, most importantly, the people they shared items like water, anointing oil and the likes together. 
During testimonies for instance, the social actors always came to the front section of the prayer camp with either family or friends to join in the sharing of the testimonies. From this behaviour, we could conclude that the act of giving testimony at MOGPA is a collaborative effort. From time to time the social actors, during testimony sessions, would describe themselves in relation to others by stressing on the role the others play in the family as well as in the construction of their identities. At times, the social actor who is testifying would go the extra mile to describe the socio-economic as well as the spiritual status of the family. For instance, in one of our visits, a lady giving a testimony stated:

...this is my child and the baby in my arms is my grandchild. I's sorry to say that my house is possessed with a lot of demonic forces..

Another also avowed,

...My children and brother were the ones who come here. As for me, I am a Methodist. They always called on me to join them for MOGPA, but I always paid deaf ear. However, I was faced with a problem and I had a dream. In the dream, something told me to come to MOGPA. Truly, ever since I came here, everything became better...one of my children who used to have problems with childbearing has even put to birth...

From the foregoing, it is evident that the social actors, during the sharing of testimonies, also circuitously presented their social identity. This is in congruence with the relational layer of identity which focuses on relationships as the locus of identity. Identity is thus seen as a mutual product, jointly negotiated and mutually formed in relationships through communication. Therefore, an individual creates his or her identity by identifying him or herself through a relationships with others, such as marital partners, co-workers, and friends.

According to Tajfel (1979), in order to increase our self-image, we enhance the status of the group to which we belong. This is also illustrated in this study as the social actors did not only come to MOGPA to pray for themselves but also to pray for their family and friends. In some situations, the social actors were seen with photographs of their relatives praying earnestly and vigorously over the images. For the participants, the photographs served as points of contact for the relatives or friends being prayed for. In others too, the social actors were seen thanking the Lord for the lives of their relatives. To these social actors, their sense of fulfillment lay in their ability to ensure that the wellbeing of their relatives is secured. Hecht and Choi (2012) affirm this when they argue that the degree to which a person's identity is embedded in relationships with others plays an important role for the individual's well-being.

Again, aside the social groups of friends and family, the concept of class structure was also visible. Although social actors had access to the grounds without difficulty, the seating arrangements were solely determined by the kind of relationship one had with the head pastor and his entourage; the social status and role one played; and other socio-political background indicators of the individual. Evidently, the study revealed that the meeting grounds were demarcated into sections. There was a section for those who had come from abroad; another for those who had been accorded the privilege of being the children of the head pastor; a place for the junior pastors and other less important members of the head pastor's entourage; and a section for the general congregants. The first three sections were so strictly reserved to the point that even when other sections became full and there were empty spaces in the reserved seats, nobody was allowed to occupy those seats until approval is sought and given by the head pastor. For instance, during one of our visits, we got there a bit later than expected, and an usher who had not met us before asked us to sit outside the meeting room since the place was full. Nonetheless, the chief usher whom we had been having constant interactions with walked to us and offered us seats at where the children of the head pastor regularly sit. During our subsequent visits therefore, we always sat at the seats of the privileged. From these manifestations, it is evident that the social actors knowingly or unknowingly, directly or indirectly structured the group in accordance with some social and class identities.

\section{Professional Identity}

Finally, the social actors also constructed professional identity. This kind of identity is one's professional selfconcept or how individuals perceive themselves within an occupational context and how it is communicated to others (Neary, 2014). The social actors in most situations identified and described themselves using their professional affiliations. They presented themselves in ways that depicted how much they valued their respective professions and as such had a strong sense of attachment to them. Through their performances, they provided descriptions of who they were professionally and voluntarily submitted narratives about their profession. This was apparent both in our interactions with some of them as well as in other performances. Those who did not belong to formalized profession, however, still managed to put themselves in a category in which they could still be identified as workers. It was intriguing to notice that sometimes, the social actors were being called with the names of their respective professions like "Madam Nurse", "Policewoman". During one of our visits, for example, we were introduced to a lady who later became one of our key informants. Before we got to know her name, she was only introduced to us as a policewoman. This happened when another informant decided to offer us help by getting other participants to facilitate our data collection. He said to us "the one person, I would want you to talk 
to is coming. She is policewoman". Just as we turned to look at the person, he called her aloud, "Policewoman" and the lady gladly responded. When asked why she responded to that, she stated that that was how everybody identified her. Just as Benveniste (1987) posits that professional roles are prestigious and provide the role holder with autonomy and often, a degree of privilege, for some of our informants, disclosing their professional identities put them in better position and gave them the opportunity to enjoy certain privileges such as getting a better place to sit and having unhindered access to the head pastor. In addition, this finding is in consonance with the enactment and communal layers of identity which indicate that identity is formed based on the perspective of others relative to what you do, what you have and how you act.

The findings further reaffirm the assertion that identities are multilayered, emergent and expressed through communication (Hecht \& Choi, 2012) because the social actors at MOGPA, through their enactments, constructed multiple identities. The identities so constructed, overlapped, interpenetrated and fused into points of inseparability (Hecht \&Choi, 2012). For most participants, the personal sense of self embodied the professional identity, ethnic identity, gender identity as well as social identity.

\section{Identity negotiation at MOGPA at Prayer Camp Services}

Identities are multifaceted. Nonetheless, premium is put on ethnic and cultural identity. It most importantly subsists on the negotiations that occur when people communicate within and across cultures (Ting-Toomey, 2015). It has been established that there is vulnerability, differentiation, and unpredictability when people find themselves within an unfamiliar cultural group. Even so, some with a strong sense of self are able to achieve a balance by understanding and respecting others' identity and allowing them to also have their sense of it (Littlejohn \& Foss, 2011). For an individual to be able to accomplish this, however, by shifting from one cultural context to the other mindfully and easily, that person must be consciously aware of the other's culture and the cultural difference; understand the importance of cultural and ethnic identities; see its importance to others and have the skill to negotiate identities through careful observation, listening, politeness, empathy, non-verbal sensitivity and collaboration (Littlejohn \& Foss, 2011). It is against this backdrop that our second research question sought to identify and analyze the kind of strategies members adopt in negotiating their identities in MOGPA gatherings. To ease analysis of informants' responses, the issues gathered from the data have been categorized under three themes: adornment, socialization and active participation.

\section{Adornment}

Body adornments is linked to a person's identity, view of self and how a person is viewed by others (Douglass, 2004). Likewise, in MOGPA, appearance through clothing illuminated another form of identity construction. Most of the social actors adorned themselves with objects that had been purposely designed and decorated with the MOGPA emblem, insignia and colors. These clothing ranged from bracelets, wrist bands, fabrics, necklaces, earrings, face towels, scarfs, kerchiefs, watches, hand fans and many others. Douglass (2004) elucidates how body adornment has the power to speak of values, beliefs, status and achievement. This is substantiated in this study when the social actors held a strong sense of belief in what they wore and the premium the placed on it. To our informants, the items had been blessed by the man of God and could be used as spiritual weapons against the devil. Aside that, to ease identification as a MOGPA member, it was imperative that, at least, the social actors adorned themselves with some of the known objects of identification within the group. Given these reasons, clothing had become one major strategy the social actors adopted in negotiating their multifaceted identity around the gender performances. Adorning themselves in the MOGPA paraphernalia gave them a sense of identity as members of MOGPA and made them easily recognizable. Below are some excerpts from the informants:

1)...I had heard of MOGPA but I didn't know they had a lot of things they adorn themselves with. It got obvious when I got here on Saturday at "Abrankese". Almost everybody I saw was in some kind of wearable...I can't say I felt uncomfortable but I didn't like seeing myself not with any of them especially when it got to the praises and worship time and we were asked to raise our MOGPA handkerchiefs in the air. All the people around me had one but I didn't and at that point I felt I was indeed in a strange man's land (laughs). So, what I did in subsequent visit was to get myself a handkerchief and even a wrist band... (Informant, 2)

...I was very happy the first time I got here but it looked like everybody was in a MOGPA paraphernalia so it made me a bit uncomfortable. Because of that, I had to ask someone who was sitting next to me where I could get some to buy and she showed me where I could get some and I went to buy them. Since then, I always have something of MOGPA on me. I have headscarf, I have wrist band, and I have all the items. So even when I am in town and people see me, they recognize me as a member of MOGPA... (FGD1, Informant 4),

...Oh! Here, as soon as you get here, you are a member of MOGPA but for somebody to recognize you as such, at least you should have something to identify yourself with. Roman and all the other churches have these kinds of things. The same thing with MOGPA. We have band, scarf, t-shirt and anything you 
like. So, for me, when I came here and I wanted people to see me and say yes (stress) I'm a MOGPA member, I immediately went to buy my scarf and the other items. I have all the MOGPA paraphernalia... (Informant, 10)

The way the men decorated themselves with the adornments differed from that of the women. Whereas the men used just one or two of the paraphernalia, the women cladded themselves with several of them. For instance, while the women would wear the MOGPA branded cloth, branded scarf, necklace, earring and a handkerchief, the men would just adorn their bodies with any of the items listed. To most of our informants, the gendered difference in dressing could be attributed to the assumption that women dressed to communicate the importance of MOGPA and its relevance in their lives to the outside world. It was also to indicate an overt display of their membership of the group. This is supported by the assertion that in using the body as a physical billboard to advertise a private statement in the public arena (Douglass, 2004) by wearing a body adornment, a woman can make an effective personal statement communicating how she feels and what she thinks about herself within the society.

\section{Socialization}

The process of identity negotiation may involve speaking, non-verbal acts, use of words, who we are with, and how we react to feelings of being judged or accepted. In this sense, our identities are shaped and molded during interactions with others (Alexander, 2011) and always emerging through interactions (Littlejohn \& Foss, 2011). Likewise, through the act of socialization, the social actors in our study negotiated their identities. The socialization process involved being and becoming member of other sub-groups and associations within the Ministry, forging friendships, having conversations, sharing views on pertinent issues in MOGPA and addressing people with the MOGPA slogan "Ablaze e. The socialization that took place was attributed to the fact there were a lot of people from multiple and diverse backgrounds. Therefore, the best way to feel at ease and familiarize oneself with the environment was to socialize. In the narratives of most of the informants, MOGPA is a very fun-filled wonderful place that also affords all members a hospitable environment. Nonetheless, because of the huge numbers and the fact that members hailed from diverse backgrounds, it takes the act of socialization to become acquainted with the people.

Language use, through exhibitions of fluency in the use of MOGPA-constructed parlances such as using certain unique words to pray, to greet and share felicitations, informants also indicated that they had to also join associations within MOGPA, engage in some form of camaraderie and, as well, interact with other members in order to feel welcome at meetings. According to our informants, the affection and friendship they received from some of the members made their stay possible and easy. During our focus group discussion, an informant said:

Yeah! I was lost...but I met some people, ok. So I quickly made friends with them, ok. I asked them questions about the meeting, ok. And the people started, you know, telling me things about the Ministry...erm so because of the friendship I made with those people eh, I was ok. They received me very well and told me certain things about the Ministry which I was very excited...since then I became involved... (FGD2, Informant 5)

Another also avowed:

I didn't know my way out the first time I got here. I had to mingle with the members and did a lot of talking. It was not too difficult because the members around were ready to assist and answer all my questions. They even helped me find a society to join. Since then I have never looked back... (Informant, 10)

One also indicated:

...hmm Madam, whenever I speak, one two, I say MOGPA, even when I'm about eating, I say MOGPA. Everything I do, I say MOGPA. So, if anything happens, people ask me when I will ever say Roman, the God of Roman...so most people know I go to MOGPA, all my church members know I go to MOGPA. And when I'm walking and I meet somebody with a band on the hand, I force myself to find out if it is a MOGPA band, then I say Ablaze... (FGD2, Informant 6).

It is a common stereotype that, in several cultures, upon being introduced into new groups, men socialize fluidly compared to women. However, our findings, relative to what transpires at MOGPA, contradict that assertion.The women, rather, freely interacted and shared ideas with others at meetings and gatherings. One informant indicated that because MOGPA is composed of more women, some men find it somehow challenging to build relationship. Unlike the women who freely converse with people to the point of even sharing items should others not have, the men find it a bit challenging. Although, they socialize, they do that in very subtle ways. In one of our numerous visits, we sat beside a gentleman. Although, we had conversation with him, it was not as fluid as the ones we had experienced with some of the female congregants.

\section{Active Participation}

In almost all social institutions, active participation is key. It is usually expected that members of a group actively and continuously involve themselves in every activity in order to keep the group thriving especially when the 
group is made up of huge membership. According to McIntosh and Alston (1982), religious participation is important for social integration and individual well-being. It is associated with involvement in other organizations and with friends and family, and it "serves as a bridge between various institutional involvements and a major source of social cohesion" (p. 876). Likewise, in MOGPA, active participation was key for social inclusion and integration into the Ministry. Therefore, the social actors vigorously involved themselves in every activity that occurred in MOGPA as a way of negotiating their identity around the gender performances. Our informants indicated that due to the nature of the Ministry in terms of size and number, it was prudent that they actively participated in the programmes and activities of the ministry in order to ensure full recognition. The informants indicated that frequenting almost all the Ministry's gatherings and putting up devout behaviours eased their inclusion at MOGPA. Such devout behaviors include immersing themselves fully in the Ministry's work by engaging in MOGPA-related theatrical performances such as singing, screaming in MOGPA parlances and dancing, helping in the arrangement and packing of Camp furnishings as well as assisting in other related activities. An informant stated:

...When I went, I saw a lot of people but I was reserved. I observed a lot of things. I observed my age mates were so much enthused with whatever that they were doing in there. So, my next visit, I also felt I should also be part of whatever was going on. So my second visit, actually I joined in their dancing, their music and their shouting... (Informant, 5)

Another informant, during our also in a focus group discussion asserted:

...when I came the first time, my work wasn't giving me time at all but because I wanted to be a member so I had to come. I have a store at Adum Pampaso but because of MOGPA, I am around anytime we meet. Both Abrankese and Cultural Center. It is difficult for me but I come for the good of it. And because there are a lot of people around, you easily get figured out if you don't involve yourself in what goes on. So, when I come, I take part in everything being done. I involve myself in everything, dancing, praying, in fact everything. Anybody who has been here for a very long time knows me... (FGD2, informant 3)

In similar vein, another informant also indicated:

...Oh! When I also came here, nobody told me to do this or that. What I did was, I did everything Reverend asked us to do. I prayed, I danced. For the Abrankese Park, I can go around it several times (laughs). Do you see the people from the 18 area who usually make noise, I'm part of them. That is what I did so everybody knows me here... (FGD2, Informant 5) 127

Among the litany of reasons given, it was evident that the social actors somewhat faced a little bit of discomfort being at MOGPA because the environment was new to them. This sides with Littlejohn and Foss's (2011) assertion that individuals may experience vulnerability, differentiation, change and unpredictability when found within an unfamiliar cultural group. However, from our findings, it was also revealed that the social actors being aware of the environment of MOGPA understood the existing culture and devised certain strategies including socialization, active involvement in Camps activities and the use of adornments as mechanisms to help ease assimilation into the new environment. This means that although there can be apprehension when found within an unfamiliar cultural group, some individuals with a strong sense of self are able to understand and respect others identity by shifting mindfully and carefully to the other culture while still maintaining their self-identity.

Swann (1996) is of the conviction that people negotiate their identities in order to establish them in ways that will increase the probability of coherence. This is exemplified in our study when the findings revealed that the social actors negotiated the identity because they wanted to integrate themselves into MOGPA.

From the study it also became clear that the negotiation process of the social actors somewhat would not have been possible without the assistance of some other members in MOGPA. As indicated earlier in the excerpts gathered from our interviews with the social actors, some informants indicated that they had to build informal relationships with others as a way of negotiating their identity. According to them, the relationship with these other social actors gave them a reason to stay in MOGPA and also aided them in their familiarization process. More importantly, their negotiation into MOGPA came to fruition because they availed themselves and other social actors were also ready to be of succor. This is buttressed by the idea that people can negotiate their identities only when the parties involved in the intercultural communication feel understood, respected and valued (Littlejohn \& Foss, 2011).

It was again evident that the identity negotiation process is inherently dependent on the context in which individuals find themselves (Erikson, 1968). The strategies adopted by the social actors mostly hinged on some social factors present in the environment in which they found themselves. To some of the informants, because MOGPA was made up of a lot of people with diverse background and also known for their unique way of dressing, it was prudent they adopted the acts of adornment, socialization and active participation as strategies to negotiate their identities.

Moreover, the social actors were seen in the state of what Ting-Toomey (2015) conceptualizes as functional biculturalism. At this state the person in the identity negotiation process must be culturally transformed. The person should be able to shift from one cultural context to the other mindfully and easily by being consciously aware of 
other people's culture, understanding the importance of cultural and ethnic identities and having the ability or skill to negotiate identities. It was gathered from the data that the social actors had multiple identities, nonetheless they were able to negotiate these identities easily in MOGPA. They did this having full knowledge of the context (MOGPA) and understood the culture surrounding it. They were also able to strategically negotiate their identity through adornment, socialization and active participation. The mechanisms used by the social actors are in congruence with the notion that the process of identity negotiation can be conducted through multiple layers of behaviors and social committal processes (Orbe, 2008).

At the Prayer Camp the involvement of the men compared to the women varied widely. Whereas the women did not hold back by freely allowing themselves to be carried away by the activities of the meeting sessions, the men lacked that easy conforming and assimilative behavior. The women enthusiastically danced, screamed and moved from their seats up and down. In addition, their responses, especially during sermon delivery and prophetic declarations signified how involved they were in the activities of MOGPA. Nonetheless, although the men took part in these activities, they were somewhat reserved. For instance, the women would dance up the front stage, form a circle and one after the other lead the rest through a particular choreography. As stressful as it appeared sometimes, they never ceased to engage themselves in such activities. Some of them sometimes, got left behind on the dancing floor but were still caught in the dancing mood even when the song ministration had ended. The men rather preferred to stand upright before their seats, clapping and singing. On one visit, we observed some ladies dancing with so much fervor. Nevertheless, the man they had come with, just clapped his hands with a few isolated gestures. To persuade him into a more active participation, one of the ladies said "wofa Yaw wo nsa? Sore na yen sa" to wit, "Uncle Yaw, won't you dance? Get up and let's dance". A more active participation by the men in the group's performances required some form of cajoling from another social actor, especially the women.

Alexander (2011) and Littlejohn and Foss (2011) establish that identities are shaped and molded during interactions with others and always emerging through social interactions. This is typified in this study which reveals that that the social actors in the process of negotiating their identities not only took on the MOGPA identity but also constructed other personally relevant identities. To most of our informants, they had become very prayerful to the extent that people outside of the MOGPA could testify to the new identity. An informant said:

...I have become very prayerful. Even my mode of prayer has changed. The people I'm in church with even say that all the time... People know I'm quiet as in I don't like talking as in the mere talking. Of course like shouting or being loud. But now people to ask me, ah you MOGPA agye m'adwen nyinara. Sei siara wo bo mpaec... (To wit, now MOGPA has taken over your mind. You are now very prayerful). You can say whatever that you want to say at any point in time, you don't even check whether people are around you, yeah! ... (FGD2, Informant 5)

Another in a similar manner answered:

... I have learnt a lot of things in MOGPA. But one particular thing I have learnt is, everything is prayer, everything. I have become very prayerful. If you read Philippians 4:6, it says be anxious for nothing and in everything but pray and petition with everything. Everything, the underlined word is everything... that means in everything, you have to pray, anything you want. When you are sick and if you want money, all you need is prayer... (FGD1, Informant, 3)

As opined by Ting-Toomey (1999), through negotiation, identities are created anytime we assert, modify or challenge our own identity as well as that of others.

\section{Conclusion}

This study probed into the kinds of identities members of MOGPA construct during prayer camp meetings and how they negotiate such identities. It became clear form the study that the social actors constructed multiple identities, including personal, gender, ethnic, social and professional identities. These multifaceted identities were made manifest through social interactions and the process of social learning. Our findings reaffirm Hecht and Choi's (2012) contention that individuals internalize their social interactions, relationships, and process them to create new identities that become expressed or enacted through communication. The findings further indicate that the social actors negotiated their identity using diverse strategies. As a result, participants at the Prayer Camp devise strategies including adornments, socialization and active participation to negotiate their identities (Littlejohn \& Foss, 2011). Thus, the social actors adopted adornment, socialization, and active participation as strategies to negotiate their identity. The findings, however, also revealed that members of MOGPA in negotiating their identities also adopted a new identity by being Prayerful. Specifically, the findings of this study illuminate the notion that the constitution of the Church and Prayer Camps impacts individuals' negotiation process. The members of MOGPA negotiate their identities having in mind the identity of the Church. Individual members, thus, negotiate their membership by engaging in group identity transformation and conformity processes that impact their religious life. In order to be involved and get to that level of complete inclusion, members had to accept the values and beliefs of the Camp and conform. 


\section{References}

Agboada, D. J. \& Ofori-Birikorang, A. (2018). "Self-Branding, Identity construction and Social Media Use by Chief Executive Officers in Ghana." New Media and Mass Communication, 67, 68-80.

Ammerman, N.T. (2005). Pillars of Faith: American Congregations and their Partners. Ewing, New Jersey: University of California Press.

Bandura, A. (1971). Social Learning Theory. New York City, NY: General Learning Press.

Benveniste, G. (1987). Professionalizing the Organization: Reducing Bureaucracy to Enhance Effectiveness. San Francisco, CA: Jossey-Bass.

Bernard, H. R. (2002). Research Methods in Anthropology: Qualitative and Quantitative Methods (3rd ed.). CA: Alta Mira Press.

Braun, V., \& Clarke, V. (2006). Using thematic analysis in psychology. Qualitative Research in Psychology, Vol.3 (2) (ISSN1478-0887), 77-101.

Bucholtz, M., \& Hall, K. (2005). Identity and interaction: A sociocultural linguistic approach. Discourse studies, 7(4-5), 585-614.

Burke, P. J., \& Stets, J. E. (2009). Identity theory. Oxford: University Press.

Butler, J. (1990). "Gender Trouble, Feminism Theory and Psychoanalytic Discourse" In L. Nicholson (Ed) Feminism/Postmodernism. London: Routledge.

Butler, J. (1999). Gender Trouble: Feminism and the Subversion of Identity.

New York: Routledge.

Chatman, C. M., Eccles, J. S., \& Malanchuk, O. (2005). Identity negotiation in everyday settings.In G. Downey, J. S. Eccles, \& C. M. Chatman (Eds.), Navigating the future: Social identity, coping, and life tasks (pp. 116140). New York: Russell Sage Foundation.Creswell, J. W. (2013). Qualitative Inquiry and Research Design: Choosing Among Approaches (4th ed.). Los Angeles, CA: Sage Publications.

Daymon, C., \& Holloway, I. (2011). Qualitative Research Method in Public Relations and Marketing Communications (2nd ed.). London: Routledge.

Douglas, H. (2004). Contemporary Body Adornment Influenced By Elizabethan, Victorian and Tribal African Design (Master's Thesis). Colorado State University.

Dowling, S. J. (2011). Constructing identity construction. Unpublished Masters Thesis, Georgia State University, 2011.

Epstein, G. S., \& Heizler, O. (2015). Ethnic identity: A theoretical framework. IZA Journal of Migration, Vol.4, $1-11$.

Erikson, E. H. (1968). Identity: Youth and Crisis. New York: W.W. Norton.

Flick, U. (2013). Qualitative Data Analysis. The Sage Handbook of Qualitative Data Analysis. London: Sage Publications

Gesler, M. E., (2013).You Is The Church": Identity and Identification in Church Leadership" (Graduate Student Theses, Dissertations, \& Professional Papers. 11.Goffman, E. (1959). The Presentation of Self in Everyday Life. Garden City, NY: Doubleday.

Golde, C. M. (1998). Beginning graduate school: Explaining first year doctoral attrition. New Directions for Higher Education, 1998(101), 55-64. doi:10.1002/he.10105.

Gubrium, J. F., \& Holstein, J. A. (2002). Handbook of interview research: Context and Method. Thousand Oaks, CA: Sage.

Halai, A. (2006). Ethics in Qualitative Research: Issues and Challenges. EdQual A Research Programme Consortium Implementing Education Quality in Low Income Countries. EdQual Working Paper Number, 4, $1-12$.

Hancock, B. (2002). Trent Focus for Research and Development in Primary Health Care: An Introduction to Qualitative Research. Trent Focus.

Hatoss, A. (2012). Where are you from? Identity construction and experiences of 'othering' in the narratives of Sudanese refugee-background Australians. Discourse \& Society, 23(1), 47-68.

Hecht, M. L. (1993). A research odyssey: Towards the development of a Communication Theory of Identity. Communication Monographs, Vol.60, 76-82.

Hecht, M. L., \& Choi, H. (2012). The Communication Theory of Identity as a Framework for Health Message Design. Audience-Centered Message Design Theory and Practice, 137-152.

Hecht, M. L., Collier, M. J., \& Ribeau, S. A. (1993). African American communication: Ethnic identity and cultural interpretation. Thousand Oaks, CA: Sage.

Hunt, S. (2002). Neither here nor there': the construction of identities and boundary maintenance of West African Pentecostals. Sociology, 36(1), 147-169.

Jackson, L. R. (2002). Cultural contracts theory: Toward any negotiation. Communication Quarterly, Vol.50(3\&4), 359-367.

Lave, J., \& Wenger, E. (1991). Situated learning: Legitimate peripheral participation. Cambridge: Cambridge 
University Press.

Lindlof, T., \& Taylor, B. C. (2002). Qualitative communication research methods. Sage Publications.

Littlejohn, S. W., \& Foss, K. A. (2011). Theories of human communication. (Vol. 10). Aufl. Long Grove: Waveland.

McIntosh, A., \& Alston, J. P. (1982). Lenski Revisited: The Linkage Role of Religion in Primary and Secondary Groups. American Journal of Sociology, Vol. 87(4), 852-882.

McPhee, R.D. \& Iverson, J. (2009). Agents of constitution in Communidad: Constitutive process of communication in organizations. (In L.L. Putnam and A.M. Nicotera (Eds.), Building Theories of Organization (pp. 89-116). NY, NY: Routledge.

Neary, S. (2014). Reclaiming professional identity through postgraduate professional development: careers. British Journal of Guidance \& Counselling, 42(2), 199-210.

Ofori-Birikorang, A. (2014). Television viewing in public spaces: Identity Construction and Evolving Urban Spaces in Metropolis in Ghana. African Journal of Interdisciplinary Studies, 7(1), 17-27

Orbe, M. P. (2008). Theorizing multidimensional identity negotiation: Reflections on the lived experiences of firstgeneration college students. In M. Azmitia, M. Syed, \& K. Radmacher, The intersections of personal and social identities. New Directions for Child and Adolescent Development, (Vol. 120, pp. 81-95.).

Orsatti, J., \& Riemer, K. (2012, January). Identity and self-presentation: from a representational to a performative lens in studying social media engagement23rd Australasian Conference on Information Systems

Swann, W. B. (1987). Identity Negotiation: Where Two Roads Meet. Journal of Personality and Social Psychology, Vol.53(6), 1038-1051.

Sweitzer, V. (2009). Towards a theory of doctoral student professional identity development: A developmental networks approach. The Journal of Higher Education, 80, 1-33. doi:10.1353/jhe.O.0034

Ting-Toomey, S. (1999). Communicating Across Cultures (1st Ed.). The Guilford Press.

Ting-Toomey, S. (2005). Identity negotiation theory: Crossing cultural boundaries. In W. B. Gudykunst, Theorizing about intercultural communication (pp. 211- 233). Thousand Oaks, CA: Sage.

Ting-Toomey, S. (2015). Identity Negotiation Theory. In J. B. (Ed.), Sage Encyclopedia of Intercultural Competence, (pp. 418-422). Los Angeles, CA: Sage.

Toulis, N. (1993) 'Beliefs and Identity: Pentecostalism among First Generation Jamaican Women in England', unpublished $\mathrm{PhD}$ thesis, University of Cambridge. 